\title{
ASPECTOS SOBRE DIREITOS HUMANOS \\ E DIGNIDADE DA PESSOA HUMANA: desconexão entre a legislação internacional, \\ o ordenamento jurídico brasileiro e a práxis da inclusão escolar de crianças com deficiência nas escolas públicas
}

\author{
CLAUDETE DE SOUZA* \\ KETHI CRISTINA SQUECOLA DO ROSÁRIO**
}

\begin{abstract}
RESUMO
Tratados e Convenções Internacionais sobre Direitos Humanos vêm sendo propostos, desde 1945, no sentido de se desenvolver a cultura mundial do acato à diversidade, o respeito a todo cidadão do mundo, possível a partir do respeito à dignidade da pessoa humana. Cada país signatário desses documentos assume a responsabilidade de criar, internamente, legislação especial que obedeça aos moldes propostos internacionalmente, e que assegurem a série desses direitos entendidos como atribuídos aos humanos para que sua dignidade seja respeitada. A pesquisa bibliográfica/documental pretende esclarecer a discrepância existente entre o vasto sistema legislativo brasileiro e o que vem sendo praticado nas escolas públicas a título de inclusão escolar da criança/adolescente com deficiência. Como objetivo principal, traça-se um paralelo com os discursos praticados sobre o tema, averiguando se a prática sobre inclusão havida nas escolas públicas
\end{abstract}

* Doutoranda em Educação na Universidade Metodista de São Paulo UMESP. Mestre em Direito pela Universidade Metropolitana de Santos UNIMES. Bacharel em Direito pela Faculdade de Direito de São Bernardo do Campo - FDSBC. Bacharel em Ciências Políticas e Sociais pela Universidade São Caetano do Sul - USCS. Advogada. Professora Universitária. claudete.souza@metodista.br.

** Doutoranda em Educação na Universidade Metodista de São Paulo UMESP. Pedagoga e Administradora, Coordenadora Pedagógica na Etec Padre José Nunes Dias e Professora Universitária na UNIP.

kethicris@hotmail.com 
vem cumprindo as inúmeras leis que tutelam esse segmento social e devem, obrigatoriamente, obedecer ao modelo da ONU, já que os Tratados ou Convenções sobre Direitos Humanos ingressam no ordenamento jurídico brasileiro com força de Emenda Constitucional.

Palavras Chave: Direitos Humanos. Dignidade da pessoa humana. Tratados/Convenções Internacionais. Legislação pátria. Inclusão escolar. Criança/adolescente com deficiência.

\begin{abstract}
International Treaties and Conventions on Human Rights have been proposed, since 1945, in order to develop a world culture of respect to diversity, respect to every citizen of the world, possible from the respect to the dignity of the human person. Each signatory country of these documents assumes the responsibility of creating, internally, special legislation that obeys the internationally proposed patterns, and that ensures the series of rights understood as attributed to humans so that their dignity is respected. The bibliographic/documentary research intends to clarify the discrepancy between the vast Brazilian legislative system and what has been practiced in public schools as school inclusion for children/adolescents with disabilities. The main objective is to draw a parallel with the speeches made on the subject, in order to verify whether the practice of inclusion in public schools has been complying with the numerous laws that protect this social segment and must, obligatorily, obey the UN model, since the Treaties or Conventions on Human Rights enter the Brazilian legal system with the force of a Constitutional Amendment.
\end{abstract}

Keywords: Human Rights. Dignity of the human person. International treaties/conventions. Brazilian legislation. School inclusion. Child/adolescent with disabilities. 


\section{INTRODUÇÃO}

A semente legislativa internacional sobre os tão propagados Direitos Humanos pode ser encontrada na Declaração Universal dos Direitos Humanos, documento estabelecido pela Assembleia Geral das Nações Unidas, no ano de 1948, reconhecendo que todo e qualquer ser humano deve ter respeitada a sua dignidade. Os fundamentos da almejada dignidade da pessoa humana são desdobramentos dos princípios da liberdade, da justiça e da paz social mundial, portanto, direcionados indistintamente às pessoas e, acima de tudo considerando sua diversidade, enquanto seres únicos e distintos.

Foi a partir de 1945 que as nações democráticas foram incitadas a criar suas legislações específicas internas para proteção aos direitos humanos de seus cidadãos, já que o ambiente pós segunda guerra mundial apresentou um número absurdo de pessoas com deficiências em todas as suas variações. Outros tratados e convenções internacionais, dentre tantos, vêm reafirmando esses direitos, a exemplo do Pacto de San José da Costa Rica e da Convenção Americana sobre Direitos Humanos, fortemente atados uns aos outros como elos de uma corrente que tenta resguardar aquilo que o ser humano tem de mais precioso, o seu direito de ser respeitado e tratado como digno representante da espécie humana.

Ao se adentrar no ambiente brasileiro e investigar sobre o cumprimento das muitas promessas constitucionais e infraconstitucionais garantidoras de direitos às minorias, um primeiro dado a considerar é que a Constituição Federal de 1988, apelidada de Constituição Cidadã, foi criada pela Assembleia Constituinte num momento em que o país tentava livrar-se do regime ditatorial. Naquele momento, povo e legisladores estavam imbuídos do firme propósito de se alcançar o Estado Democrático de Direito traçado idealisticamente na Carta Magna, guardando a expectativa do respeito aos direitos fundamentais e retorno ao exercício pleno da cidadania, plano que seria executado aos 
poucos, gradativamente, dada a extensão geográfica do país e todas suas singularidades.

É certo que o idealizado à época seria efetivado num futuro a ser alcançado em médio e longo prazos, já que não havia condições de implementar todos os compromissos assumidos pela Carta de imediato, principalmente quando se refere a políticas públicas sociais. As muitas normas programáticas contidas no texto constitucional instrumentalizariam as transformações sociais almejadas, exigindo a criação de leis específicas que garantiriam os direitos às minorias impondo, ao Estado, a concretização das políticas públicas necessárias a essa concretização. Tudo isso foi efetivado, em teoria, porém existem imperfeições, lacunas e omissões ao se observar o que vem sendo efetivado com relação à inclusão escolar de crianças e adolescentes com deficiência.

Muito foi feito, é fato, quanto a leis especiais infraconstitucionais, decorrentes do comando constitucional, a exemplo do Estatuto da Pessoa com Deficiência, de 2015, diretamente decorrente da Convenção da ONU sobre os Direitos da Pessoa com Deficiência, que está em vigor internacional desde maio de 2008, considerada como o primeiro Tratado de Direitos Humanos do século XXI. O Estatuto reformulou significativamente o Código Civil brasileiro em alguns de seus principais títulos, a exemplo do art. $6^{\circ}{ }^{1}$. Numa visão angular, este foi um comando realmente inclusivo dirigido à tutela das pessoas com deficiência. Mas isso não basta, conforme a discussão que se propõe.

\footnotetext{
Art. $6^{\circ} \mathrm{A}$ deficiência não afeta a plena capacidade civil da pessoa, inclusive para: I - casar-se e constituir união estável; II - exercer direitos sexuais e reprodutivos; III - exercer o direito de decidir sobre o número de filhos e de ter acesso a informações adequadas sobre reprodução e planejamento familiar; IV - conservar sua fertilidade, sendo vedada a esterilização compulsória; V - exercer o direito à família e à convivência familiar e comunitária; e VI exercer o direito à guarda, à tutela, à curatela e à adoção, como adotante ou adotando, em igualdade de oportunidades com as demais pessoas.
} 
A educação, de modo geral, vem sendo negligenciada pelo Estado há séculos, principalmente quando se olha para crianças e adolescentes que deveriam cursar um ensino fundamental público bem estruturado a se pretender a formação de cidadãos conscientes e atuantes. Agrava-se esta situação, se o olhar mudar de ângulo e atingir as crianças/adolescentes com deficiência, pois aí a vulnerabilidade se potencializa, somando-se à precocidade da idade. Ampliando para mais além nossa visão, alcançamos ambientes de miserabilidade aos quais grande parte da população está sujeita e que, somados a deficiência e a pouca idade, compõem um quadro muito difícil de ser confrontado, despertando indignação de quem analisa reflexivamente.

É preciso efetividade por parte do Estado, implementando políticas públicas que realmente abarquem essas pessoas extremamente vulneráveis, garantindo-lhes os direitos humanos e sua dignidade enquanto pessoas.

A segunda seção deste estudo explanará sobre Direitos Humanos e Dignidade da Pessoa humana, seguido de análise a respeito do ordenamento jurídico brasileiro a partir da Constituição Federal, conduzindo para a última parte, onde são tecidas as Considerações Finais a respeito das propostas traçadas.

\section{DIREITOS HUMANOS E DIGNIDADE DA PESSOA HUMANA}

Não é simples conceituar a expressão "direitos humanos", conforme nos esclarece Souza (2012, p. 92/93), mas pode-se valer de algumas expressões que tentam traduzir e abranger o que significa: direitos naturais, direitos do ser humano, direitos individuais, direitos públicos subjetivos, liberdades fundamentais, liberdades públicas, direitos fundamentais da pessoa humana.

Em rasa análise percebe-se que envolvidos na composição dos aludidos direitos participam juízos tais como (i) princípios indivisíveis em sua essência; (ii) abrangentes a todo o universo; (iii) obrigações que o Estado deve garantir, seja em que âmbi- 
to for. Constituem-se, também, em (iv) liberdades básicas; (v) prioritárias; (vi) pertencentes a todo ser humano; (vii) sem distinção de raça, cor, credo, condição social, econômica ou física que, (viii) se cumpridos, garantiriam a convivência digna, livre, pacífica e, acima de tudo, (ix) igualitária do ser humano em seu lar comum, o globo terrestre.

A compreensão sobre a extensão que guarda a expressão direitos humanos torna-se inerente na análise do tema inclusão escolar da pessoa com deficiência, proposta desta pesquisa. Direitos humanos são fundamentais porque sem eles é impossível à pessoa existir, se desenvolver, usufruir da vida, ter voz e imagem, ou seja, ter uma vida digna. Direitos humanos fundam-se na ideia de dignidade da pessoa humana, valor incondicional, incomensurável e insubstituível, característico e inerente à raça humana, aquilo que distingue o humano de objetos ou coisas, respeito à sua própria essência.

Ao se enfocar a época atual, Século XXI, dentre todos os sentidos que a palavra direitos sugere, pode-se destacar que nela se embute uma obrigação do Estado em legalmente preservar princípios que garantam a dignidade da pessoa humana. Se analisarmos o vocábulo pessoa, surge a noção de sujeito de direitos que é, um rótulo constitucional que pode significar um instrumento de sua defesa, promotor e realizador de sua dignidade, os direitos humanos.

Não por acaso, adequada é a lembrança de uma citação do filósofo Immanuel Kant, que subsume adequadamente a este momento de reflexão crítica:

No reino dos fins, tudo tem um preço ou uma dignidade. Quando uma coisa tem preço, pode ser substituída por algo equivalente; por outro lado, a coisa que se acha acima de todo preço, e por isso não admite qualquer equivalência, compreende uma dignidade. (KANT, 1980, p. 77). 
Portanto, dignidade é o valor imensurável que assegura ao indivíduo a busca, dentro das possibilidades e expectativas individuais, de tudo aquilo que o levará à felicidade. Dignidade é atributo garantido em todas as Constituições democráticas, porém, nem sempre concedido a todos os habitantes de um país, especialmente quando se trata do Brasil, gigantesco em dimensões geográficas, monstruoso em suas múltiplas variedades de desigualdades sociais. Dignidade é grandeza que deve ser distribuída de igual maneira a ricos e pobres, deficientes e sem deficiência. Dignidade é devida à pessoa sem se considerar merecimento, sem que seja necessário nada em retribuição, é atributo que não admite distinções, que exige equidade em sua disseminação. (SOUZA, 2012, p. 102)

Ao se encerrar esta seção, resta uma questão que deverá ser respondida no próximo título, após cotejamento mais acurado entre a legislação pátria e a rotina denunciada por especialistas nas escolas públicas do ensino público fundamental: A normatização constitucional brasileira sobre direitos humanos coaduna-se com o que se vivencia como realidade nacional em relação à inclusão escolar da criança/adolescente com deficiência?

\section{ORDENAMENTO JURÍDICO BRASILEIRO X PRÁTICA DA INCLUS $\tilde{A O}$ ESCOLAR DA CRIANÇA/ ADOLESCENTE COM DEFICIENNCIA NAS ESCOLAS PÚBLICAS}

O ambientalista Celso Pacheco Fiorillo (FIORILLO, 2013, p. 190) nomeou como piso vital mínimo o rol dos direitos dispostos no artigo $6^{\circ} 2$ da Constituição Federal de 1988, Capítulo II - Dos Direitos Sociais. Esse autor entendeu, com muita propriedade, que o elenco traçado nesse artigo, inserido após o

\footnotetext{
Art. $6^{\circ}$ São direitos sociais a educação, a saúde, a alimentação, o trabalho, a moradia, o transporte, o lazer, a segurança, a previdência social, a proteção à maternidade e à infância, a assistência aos desamparados, na forma desta Constituição.
} 
artigo $5^{\circ}$ que trata dos direitos fundamentais, deveria representar o mínimo que o Estado brasileiro obrigar-se-ia a promover para que o seu cidadão tivesse sua dignidade respeitada alcançando-se, assim, o ideal constitucional.

$\mathrm{O}$ art. $6^{\circ}$, CF elenca a educação, saúde, trabalho, moradia, lazer, segurança, previdência social, proteção à maternidade e à infância e assistência aos desamparados. Estes são os direitos fundamentais que mantêm o cidadão brasileiro vivendo dignamente, segundo a Carta, frisando-se que a educação é o primeiro dos direitos, o início do respeito à dignidade da pessoa humana. (SOUZA, 2012, p. 104).

O tema educação é longamente especificado no Capítulo III - Da educação, da cultura e do desporto, Seção I - Da Educação, artigos 205 a 214, e deve propiciar, segundo mandamento constitucional, o pleno desenvolvimento da pessoa, além de preparar o indivíduo para o exercício da cidadania, bem como promover sua qualificação para o trabalho. (BRASIL, art. 205, CF).

É fato que quando não há um ponto de equilíbrio entre o que o ordenamento jurídico propõe, como bem-estar social, e aquilo que o Estado é efetivamente capaz de sustentar, ocorre o contrário do esperado pelas normas. Ou seja, a Lei Maior que deveria ser respeitada por todos passa a ser desacreditada, já que não ocorre na prática o que preceitua a norma. No caso da inclusão escolar da criança/adolescente com deficiência existe descompasso entre os compromissos assumidos internacionalmente pelo Brasil e a postura estatal quanto à internalização, por ausência de políticas públicas positivas.

Com relação a educação das pessoas com deficiência, o Texto determinou, em seu artigo 208, inciso III, que o Estado efetivasse o "atendimento educacional especializado aos portadores de deficiência, preferencialmente na rede regular de ensino”. Todavia, a Carta Magna conta, atualmente, com 33 anos de vida, 
mas esta norma programática, especificamente, ainda não foi implementada junto à população, ou seja, o Estado brasileiro segue sem apresentar uma política pública (esta entendida como um conjunto de ações por parte do Estado para solução de problemas coletivos) que dê conta desta que é uma das grandes anomias nacionais, a inclusão escolar das crianças/adolescentes com deficiência nas mais diversas formas.

Essa intervenção precisa ser ordenada, de tal forma a se estruturar racionalmente e poder produzir os resultados pretendidos (eficácia), mudando ou estabilizando o quadro social objeto da política pública (efetividade) e, dentro das possibilidades inerentes à política que se pretende estabelecer, cumprindo as metas no menor tempo e da melhor maneira possível (eficiência). (RIANI, ,2013 p. 144-149).

Percebe-se que, a se conferir o direito constitucional à educação inclusiva, não foram previstos ambientes segregados nem salas especiais, mas alunos frequentando o ensino regular sem barreiras físicas que obstaculizem a plena participação desses alunos com deficiência, seja de que espécie for. (FRANCO e SCHUTZ, 2019, p. 244)

Ocorre que é (são) sempre política a(s) decisão(ões) que define $(\mathrm{m})$ essa intervenção estatal com pretensão a atender uma determinada necessidade pública, dependente de verbas definidas, também, politicamente, especialmente se tratando de investimento no setor social, o que retarda quando não impede a solução esperada pela minoria desamparada.

Por outro lado, a Resolução n.4, de 02 de outubro de 2009, do Ministério da Educação, Conselho Nacional de Educação, Câmara de Educação Básica, institui diretrizes operacionais para o Atendimento Educacional Especializado (AEE), a ser ofertado em salas de recursos multifuncionais ou em Centros de AEE da rede pública ou privada. A determinação do art. $5^{\circ}$ da Resolução 
é que o AEE seja realizado no turno inverso da escolarização, não sendo substituto às classes comuns e que os professores atuantes no AEE devem ter formação inicial que os habilite para o exercício da docência, além de formação específica para a educação especial. (BRASIL, 2009)

Como já dito anteriormente, nem toda a estrutura idealizada pelo Estado é efetivada, na maioria das vezes decorrente de sua própria ineficiência em alocar recursos para tal. É exatamente o que vem ocorrendo com relação a inclusão das crianças com deficiência no ensino fundamental. Foram lidos e interpretados vários autores que trabalham esse tema específico, encontrando um denominador comum entre os posicionamentos de todos eles: o expresso despreparo estatal em todos os níveis, federal, estadual e municipal, para a idealização, aplicação e concretização de bons resultados nas políticas públicas necessárias a tornar implementável a letra da lei. Seja por falta de interesse político, seja pela grande extensão territorial deste país, muitos óbices se interpõem no caminho da materialização de políticas estatais justas e adequadas que venham amenizar as muitas dificuldades enfrentadas por esse nicho de pessoas que não nascem devidamente preparadas para enfrentar o já deficitário ensino público, as pessoas com deficiência.

No ano de 2015 foi promulgada a Lei n. 13.146/2015, internamente nomeada de Estatuto da Pessoa com Deficiência (EDPC), atendendo preceitos traçados pela ONU na Convenção Internacional dos Direitos da Pessoa com Deficiência, realizada em 2009, da qual o Brasil é país signatário. (FRANCO e SHUTZ, 2019 ano, p. 245-246.). Esta legislação passou a integrar o imenso conjunto de regulamentos já existentes, é mais um documento legal que trouxe ganhos reais em muitos sentidos, tal como a gradativa compreensão, por parte das famílias das crianças com deficiência, tornando-se mais atentas aos direitos referentes à educação especial inclusiva. Porém, a família desconhece o que está faltando na escola de seu filho para que a inclusão se 
realize de forma adequada, tampouco tem ideia de que o AEE é um direito constitucional que deve ser exigido e não solicitado. Ademais, não há um sistema federal nem estadual, que monitore as necessidades específicas de cada uma das milhares de escolas da rede pública do ensino fundamental, restando aos municípios a boa vontade em destinar verbas, por sua vez sempre insuficientes, para o cumprimento do mandamento constitucional.

As pessoas com deficiência seguem invisíveis ao Estado brasileiro que insiste em ignorar seus direitos, instigando, ao mesmo tempo, que a sociedade persista considerando a inclusão como benemerência, um favor prestado e não legítima obrigação estatal. Assim, em direção contrária ao direito constitucional à educação inclusiva que não prevê ambientes segregados nem salas especiais para o atendimento às crianças deficientes, consolida-se imoral e preconceituosa institucionalização da exclusão escolar disfarçada em discurso na forma de parca integração, recorte apresentado no próximo título que ressalta a importância e significação da inclusão escolar em variadas épocas e contextos.

\section{DISCURSOS SOBRE A INCLUSÃO DA CRIANÇA/ ADOLESCENTE COM DEFICIÊNCIA NO AMBIENTE ESCOLAR}

O escopo desta discussão sobre políticas da educação e inclusão é apresentar um debate com referenciais teóricos importantes analisados durante um semestre de estudos no Doutorado em Educação promovido pela Universidade Metodista, disciplina Direitos Humanos e Inclusão, ministrada pela Profa Dra Cristina Miyuki Hashizume, provocando reflexões ao apresentar recortes sobre inclusão e as políticas de governamento.

Sardagna, estabelecendo análise fundamentada no pensamento de Foucault, informa que este autor deduz sobre a

[...] noção de discurso, como práticas que inventam o que definem, utilizando-a para fazer as articulações entre os sujei- 
tos e as práticas discursivas. O sujeito vai sendo constituído por diferentes práticas discursivas e campos de saber. Nas práticas da Educação Especial (de 1950 a 2007), encontram-se três conjuntos discursivos: A institucionalização do anormal (1950 e 1960); A distribuição dos corpos na escola (1970 e 1980) e a Inclusão e o controle dos sujeitos na escola comum (1990 e 2000). (Sardagna, 2008, p.2-3 Autor, ano, página).

[...] A articulação desses três conjuntos permite argumentar que as políticas de inclusão escolar colocam em ação práticas de governamento. ${ }^{3}$

Por discurso institucionalização do anormal entende-se a aprendizagem destinada a crianças desajustadas ou deficientes mentais (SARDAGNA, 2008 s.ct., p. 3): criada a escola especial para recuperar crianças retardadas ou de difícil aprendizagem. A necessidade de institucionalização era justificada pela necessidade de corrigir "crianças portadoras de deficiências emocionais, físicas ou mentais", visando recuperá-las e ajustá-las ao meio social. Dava suporte ao trabalho pedagógico discursos psicológicos, médicos e da assistência social. Essa prática "avalia, compara e classifica, posicionando o indivíduo em relação à norma como o ‘aluno excepcional', o ‘aluno deficiente`, a ‘criança retardada', a “criança subdotada”".

A segunda modalidade discursiva, a distribuição dos corpos na escola, era articulada com a primeira espécie. Entre 1970 e 1980 , principalmente, multiplicaram-se os espaços chamados "classes especiais" e "escolas especiais", com intuito de dispor os corpos que deviam ser normalizados e vigiados eficazmente. As normalidades e anormalidades passam a ser classificadas e hierarquizadas através do conceito "média" estatística.

Governamento, segundo Foucault, é o conjunto de "técnicas e procedimentos destinados a dirigir a conduta dos homens. Governo das crianças, governo das almas ou das consciências, governo de uma casa, de um Estado ou de si mesmo" (FOUCAULT, 1997, p.101). 
Ainda na opinião de Sardagna (s.ct.2008, p. 7), uma "arquitetura" de vigilância dos alunos rotulados por esses discursos os dispõem em classes ou escolas especiais, dessa forma facilitando o controle individual e, também, o controle do grupo em relação aos outros. Várias formas diferentes de rotulação eram utilizadas: criança com problema; educando-problema; alunos-problema... A Escola Nova passa a utilizar o conceito de criança problema ou criança difícil como sinônimo do aluno que não se encaixava socialmente ou na aprendizagem-padrão.

$\mathrm{Na}$ fase inclusão e o controle dos sujeitos na escola comum, vigente de 1990 a 2000 abrangendo o início do século XXI, tem-se a inversão do discurso: a criação de lugares segregados destinados aos anormais deixando de ser um objetivo, a ordem agora é trazer esses alunos para junto dos demais. Uma nova organização do espaço da sala de aula deve receber aquele concebido como "aluno incluído", reposicionando-o em melhores condições, mudança que se alinha com as novas formas de governamentalização.

Projetos educacionais preocupam-se em utilizar novos termos inclusivos: "direito à cidadania”, "respeito às diferenças”, “inclusão social”, “diversidade cultural. Entende-se como necessária a formação continuada em educação inclusiva para professores e equipes diretivas. (SARDAGNA, 2008 p. 11) As metas do Ministério da Educação traçam o rumo do "Todos pela Educação” (MINISTÉRIO DA EDUCAÇÃO, BRASIL, 2021), imperativo que delega à toda a sociedade a corresponsabilidade para que toda criança/adolescente tenha acesso a Educação Básica de qualidade, independentemente de deficiência ou não.

Por fim, as políticas de inclusão escolar empalideceram a Educação Especial, pretendendo-se que com a difusão da inclusão escolar as práticas normalizadoras estejam em toda e qualquer escola, utilizando-se do lema "inclusão de todos na escola comum". "A cada época e contexto as políticas de inclusão escolar colocam em ação práticas de governamento dos sujeitos, operando e sendo operadas por mecanismos de normalização e de regulação permanentes". (SARDAGNA, 2008 ano, p. 13) 
Passa-se, a seguir, a discorrer sobre o perigo que representa para os sujeitos um laudo médico quando se pretende a inclusão escolar de crianças/adolescentes com deficiência.

\subsection{Estigmatização da criança/adolescente com deficiência pelo "Laudo Médico": uma afronta à dignidade da pessoa humana}

Um dos objetivos deste texto é discutir de forma empírica as práticas do educador sustentando a ponderação referente aos direitos e deveres, pois havendo o equilibro entre estes pilares, teríamos consonância, seria enriquecedor para ambas as partes, mas ainda é muito difícil conseguir tudo isso na prática.

O discurso da medicalização, muitas vezes desnecessária, induz em certos momentos subdivisões, expõe a ideia de segregação, de habilidade biológica pertencente apenas a alguns, não considerando as interações humanas. Não se pode considerar como definitivo e certeiro um laudo médico apenas por ter sido emitido por alguém protegido por um jaleco branco que impõe "autoridade de Diagnóstico", desconsiderando o trabalho em equipe como o diálogo com psicopedagogo e as impressões do professor de sala de aula. A se buscar a razão somente no conhecimento técnico, pode-se estigmatizar para sempre uma criança como passível de determinado tratamento médico recomendado.

Por muitas vezes o aluno com deficiência é submetido a medicalização, trazendo angústia para a própria equipe pedagógica que acompanha essa criança diariamente, observando e tendo experiências, conhecendo das dificuldades e das oportunidades que são criadas para alavancar a prática pedagógica afim de desenvolver suas habilidades e competências. A lógica medicalizante envolve vários profissionais, desqualifica o saber do professor que não se sente seguro em bater contra um diagnóstico, além do fato que há um excesso de valorização do discurso médico, que sempre vence. É uma questão ou jogo de poder, segundo Foucault. Esses saberes têm peso maior do que 
os demais saberes. Geralmente o professor se entrega, concorda que não tem conhecimento específico do que foi diagnosticado, apesar de discordar disso.

As famílias, aflitas e desconhecedoras sobre as reais razões das dificuldades da criança, por vezes buscam o caminho do laudo médico acreditando lhe ser salutar, naquele momento, para que não ocorra perdas ou prejuízos pedagógicos na escola. Porém, todo parecer deve ser interdisciplinar, não existe diagnóstico para a criança com deficiência, mas sim uma hipótese-diagnóstico, aliado ao parecer do professor, do pediatra, dos pais. Mas, sabe-se que na realidade a mãe vai ao pediatra, geralmente do posto de saúde, que receita o remédio que ela está pedindo. A criança é rotulada e não consegue aprender exatamente em razão do diagnóstico, extraviam-se suas oportunidades num momento tão importante em que está em formação, perde a chance de se desenvolver por ser um aluno estigmatizado com um diagnóstico. Uma das autoras analisadas rotula esse equívoco como "profecia autorrealizadora" referindo-se ao processo no qual uma pessoa, ao acreditar na possibilidade da ocorrência de determinados eventos, contribui para que de fato eles ocorram sem perceber sua prejudicial participação (PATTO, 1997). Os docentes envolvidos precisam trabalhar na humanidade, atitude essencial para que a ação política de cada um deles seja um diferencial na vida do educando e na construção de uma sociedade justa, fraterna e solidária.

O fracasso escolar segue presente por meio do estereótipo que o/a professor/a e a escola colocam no/a estudante, e que o classifica na sala de aula e na escola. Retomando o conceito de profecia autorrealizadora, para Patto sua superação dependeria:

[...] de uma mudança de olhar: ao invés de justificá-lo pelas carências das crianças (o que ele não sabe, as habilidades que ela não tem, sua condição de carência global, enfim), assumi-lo mais, diz respeito a um direito fundamental do 
ser humano: o direito de aprender, o direito ao ensino, o direito ao acesso aos bens culturais (PATTO, 1997, p. 238).

Esta é uma questão a ser enfrentada pela sociedade, já que não somente a formação de professores de educação inclusiva exige uma análise considerando múltiplos fatores. Deve-se considerar, também, a estrutura física do ambiente educacional, como salas equipadas para atender sujeitos com as mais diferentes deficiências, realização de diagnóstico para a utilização de sala de recursos, equipe especializada patrocinada pelo município, para que o aluno possa ter atendimento adequado e, por meio da intervenção de uma comissão habilitada, se conclua o melhor a ser feito em cada caso concreto.

Importante compreender como diagnósticos, medicalizações sem necessidade e a patologização de comportamentos e processos de aprendizagem podem alterar/influenciar o futuro de crianças, mudando assim o percurso de uma vida salutar como alunos, indivíduos e cidadãos e até mesmo enquanto futuros trabalhadores.

\subsection{Biopoder e políticas públicas Sobre inCLus Ão ESCOLAR}

Necessário entender por que os sujeitos diferentes da maioria são alvos de perseguição discriminatória. De onde decorre a cultura social que discrimina e rejeita, impensadamente, às PCD? Os estudos de Foucault a respeito do biopoder podem esclarecer alguns pontos significativos.

O biopoder seria o controle constante da vida pelo sistema capitalista, mas também nos ajuda a entender a ânsia das instituições para que esse indivíduo que vai sendo formado da escola, seja alguém que ajude na construção de uma sociedade produtiva. Essa força atravessa e modela a sociedade, é uma modelagem quando pensamos em inclusão e, mais do que nunca, sentimos não ser discriminatório, muitas vezes é intencional, podendo parecer que é uma coisa individual maquiavélica. 
"Biopoder corresponderia ao conjunto dos mecanismos pelos quais aquilo que, na espécie humana, constitui suas características biológicas fundamentais, vai poder entrar numa política, numa estratégia política, numa estratégia geral do poder" ( Michel Foucault, 2008, p. 35 apud FURTADO e CAMILO, 2016, p. 3 ).

Portanto, interpretando estudos profundos realizados de Foucault, pode-se perceber biopoder como

as práticas, surgidas no ocidente moderno, voltadas à gestão e regulação dos processos vitais humanos. O poder sobre a vida instala-se como modo de administrar populações, levando em conta sua realidade biológica fundamental. (Foucault, 1976 apud FURTADO e CAMILO, 2016, p. 35).

Com isso, engendra-se um imaginário em que se associa miséria e crime ou miséria-deficiência-patologia, o que dá origem a atitudes repressivas e projetos sociais governamentais negativamente discriminatórios, tais como vem ocorrendo com crianças/ adolescentes com deficiência. A governamentabilidade, como o biopoder, é uma razão de Estado, detentor desses dispositivos todos, esses mecanismos que regulam a todo modo de governo. (ARELARO e SILVA, 2017; LOPES e FABRIS, 2017)

Segundo Hashizume (2020), o Plano Nacional de Educação de 2008, na perspectiva da educação inclusiva, determina que a educação especial promova, de forma articulada ao ensino regular, o atendimento necessário aos alunos que apresentam deficiência (deficiências, transtornos globais de desenvolvimento, superdotação e altas habilidades). Nesse sentindo, segundo a autora, faz-se necessária uma discussão sobre o biopoder, ou seja, o controle estrutural sobre o corpo "anormal” (HASHIZUME, 2020). O biopoder, conceito baseado em constructos teóricos de Foucault (1979;1997), realiza uma análise nesses períodos antigos, cons- 
truindo uma teoria em cima de modelos que ele não generalizou, mostrando que existia alguma similaridade no controle social, visto principalmente a partir das instituições. Então, o panóptico que controlava as pessoas dentro das prisões, por exemplo, tinha um controle parecido com o que acontece nas escolas, nas disciplinas escolares: andar em fila, sentar-se em fileira, levantar a mão, então sem generalizar, mas analisando essas especificidades das instituições, ele percebe que existe uma forma de controle da vida a partir dessas pequenas práticas de poder, poderes locais e novas relações de poder que se aplicam à vida.

O que pode, por exemplo, ser considerado normal no caso de crianças/adolescentes? Se são pessoas ainda em fase de desenvolvimento, como é que os valores acontecem para eles, como é que a escola consegue se atualizar e se flexibilizar em relação a essa nova clientela que está chegando? Não nos parece que a escola está preparada para lidar com as crianças e adolescentes contemporâneos, pois muitas delas conservam, ainda, o conceito ultrapassado de que famílias são aquelas compostas por pai, mãe e filhos do mesmo pai; caso não seja esta a configuração, rotula-se como uma família desestruturada e isso influencia no tratamento dispensado ao aluno. É bem comum ouvir de diretoras e professoras a respeito de determinada criança: "Também, como ela pode ser normal se tem uma família dessas?"

É complexo isso, pois na realidade ocorre a estigmatização do indivíduo com deficiência, violando totalmente seus direitos da personalidade. Muitas vezes as famílias não querem que uma criança deficiente esteja na mesma sala de seu filho, entendendo que este pode ser "prejudicado". Discursos preconceituosos são reproduzidos mesmo que a pessoa não tenha tido contato com um aluno com deficiência. Dessa forma, cobrar as possibilidades de exercício de cidadania daquele que tem deficiência, vai contra uma visão de escola inclusiva.

A escola precisa pensar em formas de lidar com essas situações, porque atualmente não é mais uma questão de opinião 
é uma questão de lei ordenando o respeito aos direitos fundamentais da pessoa com deficiência. Por isso é importante que a escola se atualize em relação ao tema evitando transgressões à lei, da mesma forma que a pessoa com deficiência se inteire da tutela legal, que é ampla e abrangente. A legislação a protege garantindo educação de qualidade em qualquer escola pública ou privada, com direito a matricular-se onde quer que deseje ou lhe seja conveniente estudar. Assim sendo, a escola que opor-se a operar o que está na lei pode responder frente à justiça em relação a essa negativa.

As reflexões e propostas apresentadas por Arelalo e Silva (ARELARO e SILVA, 2017) traduzem importantes indicadores de qualidade da atenção às pessoas com deficiência e podem orientar projetos e ações de políticas públicas nesta área, com a intervenção direta das pessoas com deficiência na afirmação de sua vida independente, que amplie o viver numa sociedade que se propõe inclusiva e emancipadora, que transforma o impossível de hoje, no possível de amanhã.

Nesse sentido, uma população ignorante e desinformada é muito mais fácil de ser manipulada, recebendo como favores e benemerências as ações devidas legalmente pelo Estado, acatando um discurso de que as coisas estão bem e todos devem se conformar com o que lhes foi dado, pois é o possível para aquele momento e deve ser aceito pacificamente. Segundo as autoras ora analisadas, deve haver a participação e percepção da pessoa com deficiência, defendendo diretamente seus direitos, ao invés de se contentar em ficar escondida e receber, agradecida, o pouco que lhe é dado. (ARELARO e SILVA, 2017)

O que vem ocorrendo ao longo de séculos é a intervenção das pessoas que não têm deficiência, respondendo por aquelas com deficiência. Ora, não há como defender com propriedade um direito da pessoa com deficiência, a partir desse olhar de quem não tem deficiência. As pessoas vêm decidindo por elas, avaliando e construindo as políticas públicas por elas, mediante 
um discurso inadequado já que decorrente de uma visão de pessoas que não têm deficiência. "Nada sobre nós, sem nós". Esta é a fala que deve se transformar em realidade a partir do momento que as PCD's estejam devidamente preparadas para que, em situações de violação de direitos humanos, se coloquem de forma argumentativa, exercendo também seus deveres, tendo a visão cidadã de alguém que precisa ser respeitado por estar na lei.

A realidade não é o que as pessoas dizem sobre, há muitos estudos referentes às políticas públicas que se baseiam em percepções e representações sobre a realidade, então essas políticas sociais são importantes:

pessoas com deficiência representam um grupo ainda com todas as particularidades das situações de deficiência e da diferenciação de demandas, alvo de um conjunto de ações das políticas sociais Primeiro porque necessitam que haja ações que atendam suas demandas específicas, de forma direta ou não, permanente ou transitoriamente; em uma ou mais das áreas com por exemplo saúde e educação (ARELARO e SILVA, 2017, p. 52).

Em se tratando de políticas públicas, muitas vezes as pessoas com deficiência não têm voz, não são vistas como primeira pessoa, entendidas como dignas de dó. Importante que se desenvolva cultura que rompa com esse tabu, já que as pessoas com deficiência não podem ser privadas de independência e autonomia. São seres humanos como qualquer outro, que necessitam de apoio e incentivo para vencer as muitas barreiras impostas pela limitação física ou mental, mas que nem por isso são pessoas que não podem alcançar autonomia, desenvolver habilidades, adquirir competências como todas as demais.

A expressão aristotélica "Devemos tratar igualmente os iguais e desigualmente os desiguais, na medida de sua desigualdade”, mandamento ético pensado há tantos séculos permanece 
sem efetivação. Alguém que é privado de algumas estruturas biológicas deve ter a chance de tentar superar aquela deficiência, ter acesso à educação de qualidade junto a todas as demais pessoas, sem qualquer indício de segregação.

A inclusão de verdade tem que acontecer na sala normal, com os outros. O que ocorre na sala de recursos exige conhecimento individualizado, promove indústrias de medicamentos, de materiais. A super especialização produz um nicho de interesse que não vem em benefício das PCD, mas segrega ainda mais uma parcela deles. Esse é um fato real e legal. Não lhes pode ser negado conforme vem ocorrendo, direitos que são inerentes ao ser humano. Estado, sociedade e família devem, juntos, promover o acesso das pessoas com deficiência a todos os direitos que lhes são garantidos, na forma constitucional e infraconstitucional.

Refletir significa perceber que não é porque existe uma vontade de neutralizar todas essas diferenças que elas vão ser exterminadas e o final será feliz, como nos contos de fada. Sempre existirá a resistência do que foge à curva normal do conceito estatístico: a normalidade vem de um conceito estatístico, normal é aquilo que é mais recorrente, ou seja, em qualquer contagem estatística quando se foge da curva, normalmente significa que você está no índice e que está fora da média, ou muito acima ou muito abaixo; o que é anormal é aquilo que está fora da norma está muito diferente da média. O que encontramos na contagem da sociedade como um todo, esse conceito de anormal que era o conceito estatístico e simplesmente foi somado ao conceito patológico ou colocaram que o normal da estatística fica atrelado a alguma coisa doentia.

\section{CONSIDERAÇÕES FINAIS}

Com este trabalho tenta-se avaliar, a partir dos Tratados e Convenções Internacionais versando sobre direitos humanos aos quais o Brasil adere, lhes atribuindo status de Emenda Constitucional, a existência de consonância com as leis internas que 
obrigatoriamente devem cumprir as ordens emanadas internacionalmente.

Utilizou-se, também, da literatura especial sobre direitos humanos e inclusão, inserindo os diálogos havidos em aula referentes a educação inclusiva que integra os alunos com necessidades especiais em escolas regulares, por meio de uma abordagem humanística. Essa visão entende que cada aluno tem suas particularidades e que elas devem ser consideradas como diversidade e não como problema.

Constatou-se que há discrepância entre os comandos emanados da legislação, inclusive a constitucional, e a prática a respeito da inclusão de crianças/adolescentes na educação fundamental da rede pública de ensino. Ausentes, pois, políticas públicas positivas que realmente transformem o atual e insuficiente sistema de integração da criança/adolescente com deficiência para a idealizada inclusão, ainda não efetivada a contento.

O Estatuto da Pessoa com Deficiência, em vigência desde 2015, é obra diretamente decorrente dos comandos protetores gerados pela realização da Convenção da ONU sobre os Direitos da Pessoa com Deficiência, realizada em 2008. Esta lei especial provocou boas práticas beneficiando esse nicho social, inclusive atribuindo a essas pessoas capacidade plena para atuação na vida civil. O EPCD tenta provocar conversões na visão brasileira a respeito das PCD, cobrando do Estado e da sociedade a efetivação de todos os direitos intrínsecos ao respeito à dignidade humana que não lhes estejam sendo cumpridos. É fato que uma cultura não pode ser transmutada em curto espaço de tempo, já que hábitos preconceituosos e discriminatórios vêm sendo cultivados há séculos, conforme traçado no quarto título e seus subtítulos, demonstrando que discursos insensatos a respeito da deficiência, em suas múltiplas espécies, já não acontecem nas formas vetustas denunciadas.

A expressão "utopia”, em grego, significa "não lugar, lugar que não existe". Nos dicionários, o conceito que se forma a 
partir da grafia desse vocábulo é correspondente a um "projeto irrealizável; uma quimera". Por isso esse termo passou a designar qualquer ideal político, social ou religioso, cuja realização seja difícil ou impossível. Resta um questionamento, encerrando esta pesquisa: o respeito à dignidade da pessoa humana trazida na Constituição Federal de 1988 tendo como destinatário todo e qualquer cidadão, pode ser considerada uma utopia?

Após a análise realizada, conclui-se que nem sempre o constitucionalmente estabelecido consegue ser concretizado em espaço temporal adequado. Quando se transporta o comando legal para o mundo real onde, a exemplo da inclusão escolar das crianças/adolescentes com deficiência, o Estado deve se empenhar na extirpação das discrepâncias e miopias internalizadas por seu corpo administrativo. Políticas públicas positivas devem ser implementadas sem tantos entraves, aliviando o sofrimento e vulnerabilidade de pessoas ainda em formação, sujeitos que são alvos de tantos direitos que não ocorrem na prática. $O$ emperramento estatal é uma realidade que conta com grande contribuição de interferências das mais variadas, sejam elas políticas, econômicas, sociais ou culturais, mostrando uma conivência insalubre com tantos obstáculos para concretização dos ideais constitucionais.

\section{REFERÊNCIAS}

ARELARO, L.R.G.; SILVA, S. (Orgs.). Direitos sociais, diversidade e exclusão: a sensibilidade de quem as vive. Campinas, SP: Mercado de Letras, 2017.

BRASIL. Ministério da Educação. Plano Metas Compromisso Todos pela Educação. Disponível em: https://todospelaeducacao.org.br/. Acesso em: 01 nov. 2021.

BRASIL. Ministério da Educação. Resolução no. 4, de 02 de outubro de 2009. Disponível em: https://www.gov.br/mec/pt-br. Acesso em: 18 out.2021.

BRASIL. Presidência da República. Lei n. 13.146/2015 - Lei Brasileira de Inclusão da Pessoa com Deficiência. Estatuto da Pessoa com Deficiência. 
Disponível em: http://www.planalto.gov.br/CCIVIL_03/_Ato201. Acesso em nov. 2021.

CORRÊA, Camila Bottero; LOCKMANN, Kamila. Os discursos inclusivos e seus efeitos sobre o discente normal: estratégias de governamento. Revista Interinstitucional Artes de Educar, Rio de Janeiro. Rio de Janeiro, v. 6, n. 3, p. 1094-1112, set./dez., 2020.

FIORILlO, Celso Pacheco Filho. Curso de Direito Ambiental Brasileiro. 14. ed. São Paulo: Editora Saraiva, 2013.

FOUCAULT, M. Microfísica do poder. Rio de Janeiro: Graal, 1979.

Resumo dos Cursos do Collége de France. Rio de Janeiro: J. Zahar, 1997.

FRANCO, Adriana M. dos Santos; SCHUTZ, Gabriel Eduardo. Sistema educacional inclusivo constitucional e o atendimento educacional especializado. Saúde em Debate. Rio de Janeiro, v. 43, n. 4, p. 244-245, dez., 2019.Disponível em: . Acesso em: 27-28 out. 2021.

, Rio de Janeiro, V.43, N. Especial 4, p.244-255, dez 2019. Disponível em: https://www.scielo.br/j/sdeb/a/F9Tb3pwLq8vFDrn3yzhndFg/abstract/?lang=pt. Acesso em 27 e 28 out 2021.

FREIRE, Paulo. Pedagogia da Autonomia. 41. impressão, São Paulo: Editora Paz e Terra, 2010.

FURTADO, Rafael Nogueira; CAMILO, Juliana Aparecida. O conceito de biopoder no pensamento de Michel Foucault. Revista Subjetividades. Fortaleza, v. 16, n. 3, dez., 2016. Disponível em: http://pepsic.bvsalud.org/ scielo.php? script=sci_arttext\&pid=S2359-07692016000300003. Acesso em: 21 nov. 2021.

HASHIZUME, Cristina Miyuki. Trabalho docente na inclusão: biopolítica e direitos humanos. HUMANIDADES \& INOVAÇÃO, v. 7, p. 1-20, 2020.

HASHIZUME, Cristina Miyuki. Resenha. Eccos Revista Científica. São Paulo, n. 56, p. 1-7, jan./mar., 2021.

, São Paulo, n. 56, p. 1-7, e18627, jan/mar., 2021.

HASHIZUME, Cristina Miyuki; MORAIS Creudimar Silva. In-exclusão escolar: reflexões epistemológicas e práticas sobre a aprendizagem do aluno com defi- 
ciência auditiva na escola regular. Cadernos de Pós-graduação. São Paulo, v. 20, n. 1, p. 111-127, jan./jun. 2021. Disponível em: https://doi.org/10.5585/ cpg.v20n1.18665. Acesso em: 15 nov. 2021.

KANT, Immanuel. Fundamentação da metafísica dos costumes. Coleção os pensadores. São Paulo: Abril Cultural , 1980.

LOPES, Maura Corcini; FABRI, Eli Henn. Inclusão \& Educação, 1 ed; 2 reimpressão. Belo Horizonte: Autêntica Editora, 2017.

MORAES, Alexandre. Direito Constitucional. 19. ed. São Paulo: Atlas S.A., 2006.

Direitos Humanos Fundamentais: comentários aos artigos $1^{\circ}$. a $5^{\circ}$. da Constituição da República Federativa do Brasil, doutrina e jurisprudência. São Paulo: Atlas, 1997.

MORUS, Thomas. A Utopia. Tradução: Luiz de Andrade. Biblioteca Clássica. Vol. XVIII, 3. ed. São Paulo: Atena Editora, s.d.

PATTO, Maria Helena Sousa. Introdução à psicologia escolar. 3 ed. São Paulo: Casa do Psicólogo. 1997.

PILATI, Alexandre Simões.et al. (Org.) Educação, pobreza e desigualdade social: a iniciativa EPDS na Universidade de Brasília.2017-2018. Brasília: Editora Universidade de Brasília, 2020.

RIANI, Frederico Augusto d'Avila. Constituições programáticas, funções estatais, políticas públicas e a (in)competência do judiciário. Revista Sequência. Florianópolis , n. 66, p.137-160,-ano Julho de 2013. Disponível em https:// www.scielo.br/j/seq/a/n4dbNjDMxjHGRp5T7crd3Fh/abstract/?lang=pt. Acesso em: 28 out. 2021 .

SARDAGNA, Helena Venites. Práticas normalizadoras na educação especial: da institucionalização do anormal à inclusão escolar, 2008. Disponível em GT15-5510--Int (anped.org.br). Acesso em: 31 out. 2021.

SOUZA, Claudete. Algumas considerações e questionamentos sobre direitos humanos: a tutela oferecida pela Constituição Federal de 1988 e sua efetiva execução. Revista do Curso de Direito. São Bernardo do Campo, v. 9, n. 9, p. 91-126, 2012. Disponível em: https://www.metodista.br/revistas/revistas-ims/index.php/RFD/article/view/3544. Acesso em: 15 nov. 2021. 